\title{
BMJ Open Feeling the pressure: a cross-sectional study exploring feasibility of a healthcare Pop-Up for intraocular pressure measurements in shopping centres in England
}

\author{
Laura A Edwards (D), Deanna J Taylor, Peter Campbell, Rakhee Shah, \\ David F Edgar, David P Crabb
}

To cite: Edwards LA, Taylor DJ, Campbell P, et al. Feeling the pressure: a cross-sectional study exploring feasibility of a healthcare Pop-Up for intraocular pressure measurements in shopping centres in England. BMJ Open 2019;9:e030523. doi:10.1136/ bmjopen-2019-030523

- Prepublication history and additional material for this paper are available online. To view these files, please visit the journal online (http://dx.doi. org/10.1136/bmjopen-2019030523).

Received 19 March 2019 Revised 14 August 2019 Accepted 24 September 2019

Check for updates

(C) Author(s) (or their employer(s)) 2019. Re-use permitted under CC BY-NC. No commercial re-use. See rights and permissions. Published by BMJ.

Division of Optometry and Visual Science, School of Health Sciences, City University London, London, UK

Correspondence to Professor David P Crabb; david.crabb.1@city.ac.uk

\section{ABSTRACT}

Objectives To test the hypothesis that a shopping centre Pop-Up health check combining an intraocular pressure (IOP) check with a general health check (blood pressure $(\mathrm{BP})$ ) is more readily accepted by the general public than an IOP check only. We investigate public awareness of IOP compared with BP and the feasibility of measuring IOP in large numbers in a Pop-Up.

Design A cross-sectional study using a tailor-made healthcare Pop-Up.

Setting The 'Feeling the Pressure' Pop-Up was sited in eight regionally-different shopping centres in England. Participants Adult members of the public in shopping centres.

Methods On one day we measured IOP only and on another measured BP and IOP. IOP was measured by Icare IC100 tonometer (Helsinki, Finland). Potential participants were asked about their awareness of IOP and BP and when they last visited their optometrist.

Results More people attended the combined BP + IOP days (461; $60 \%$; $95 \% \mathrm{Cl} 56 \%$ to $64 \%$ ) than IOP-only days (307; $40 \%, 95 \% \mathrm{Cl} 37 \%$ to $43 \%$ ) over 16 days of testing. We recorded IOP in 652 participants (median (IQR) age and IOP of 54 (42 to 68) years and 13 (11 to 15) $\mathrm{mm} \mathrm{Hg}$, respectively). Fewer people reported awareness about IOP (19\%, 95\% Cl 16\% to 23\%) compared with BP (71\%, 95\% Cl $66 \%$ to $75 \%)$. Of 768 participants, $60(8 \%)$ reported no previous optometric eye examination and 185 (24\%) reported $>2$ years since their most recent examination. Conclusions Measuring IOP in large numbers of the public via a shopping centre Pop-Up is feasible. Public engagement was greater when a BP check was offered alongside an IOP check, suggesting unfamiliar health checks can be promoted by aligning them with a more familiar check. Our findings hint at strategies for public health schemes that engage the public with their eye health.

\section{INTRODUCTION}

Retail short-term sales spaces, often referred to as Pop-Ups, are a common sight in shopping centres and other public spaces. They have become a popular form of retail; in

\section{Strengths and limitations of this study}

- This is the first study to investigate the use of a PopUp for the purpose of blood pressure (BP) and intraocular pressure (IOP) measurements in a shopping centre.

- We examined a large number of people, with a throughput of one person being tested every 10 mins in the Pop-Up.

- Response bias and recall bias likely affect results on public awareness of IOP and BP and self-reporting of most recent examination (if any) with an optometrist.

- We did not report on participant ethnicity or explore reasons for people not wanting to be examined.

the year 2015 it was reported that over $44 \%$ of people in the UK had visited a Pop-Up within the previous 12 months. ${ }^{1}$ A Pop-Up is often tailor-made to a specific space, offering a limited window of time for people to engage. ${ }^{23}$ Principally, Pop-Ups aim to do something different, unusual and interesting in order to catch the attention of the public. The idea of temporary Pop-Ups for health checks has not been widely explored ${ }^{4}$ and is the theme of this paper. Specifically, we investigated the measurement of intraocular pressure (IOP), and the public's awareness of IOP using a Pop-Up environment.

Glaucoma is an umbrella term for a group of degenerative conditions of the optic nerve, which can cause irreversible loss of the visual field (VF). Primary open angle glaucoma (POAG), the most common form in the UK, is a chronic, age-related disease and is often asymptomatic until it progresses to a more advanced stage. ${ }^{5}$ POAG is responsible for a significant proportion of sight impairment in England and Wales. ${ }^{6}$ Elevated IOP is a major risk factor for $\mathrm{POAG}^{5}$ and, consequently, IOP 


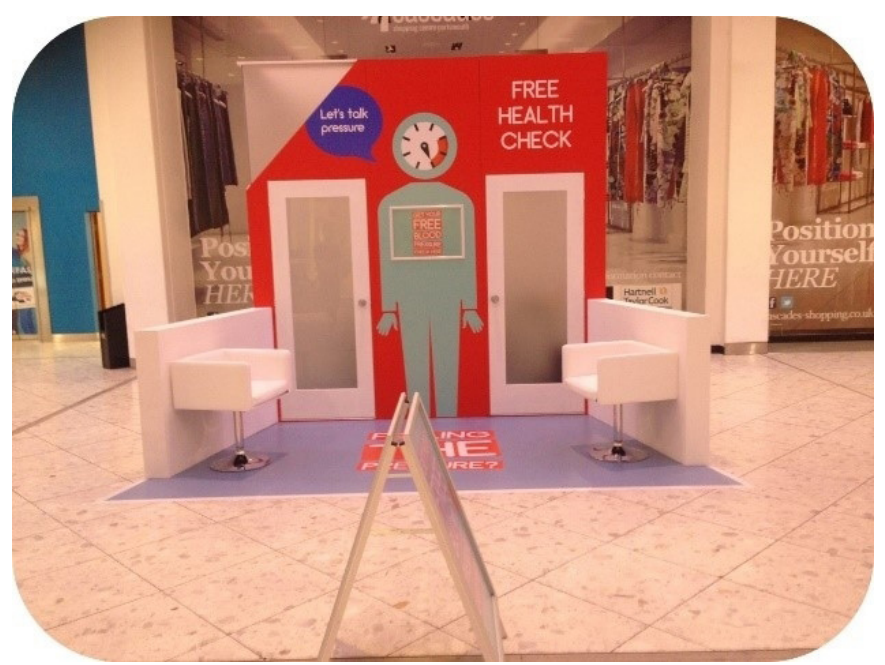

Figure 1 The 'Feeling the Pressure' Pop-Up.

is an important measurement in determining if a patient is at risk of developing glaucoma, otherwise known as a 'POAG suspect'. Elevated IOP is also associated with other forms of glaucoma, notably primary angle closure glaucoma, and IOP measurement is equally important in identifying these glaucoma suspects.

In the UK, IOP measurement is carried out by community optometrists as part of a routine eye examination when clinically appropriate. At the time of the study, there were joint guidelines issued by the College of Optometrists and Royal College of Ophthalmologists on the referral of glaucoma patients and glaucoma suspects into secondary care. ${ }^{7}$ This guidance advised that optometrists should perform central VF assessment using standard automated perimetry, optic nerve assessment, IOP measurement using Goldmann applanation tonometry (GAT), along with peripheral anterior chamber configuration and depth assessment. Subsequent to the completion of data collection for this study this guidance has been superseded by the National Institute for Health and Care Excellence (NICE) 2017 Glaucoma guideline. ${ }^{8}$ Currently, most referrals for suspect glaucoma into secondary care are the result of opportunistic case finding by optometrists; over $90 \%$ of glaucoma referrals are initiated by optometrists. $^{9-11}$

A person's knowledge and awareness of disease, level of income and age are important factors in case finding, diagnosis, treatment adherence and prevention of a disease. This is true for both ocular ${ }^{12} 13$ and systemic ${ }^{14}$ diseases. Specifically, it has been shown that lack of awareness of the importance of regular eye examinations results in a person being less likely to visit an optometrist. ${ }^{15} 16$ This lack of awareness and its consequences, among other barriers to visiting the optometrist, result in case finding by community optometrists being an imperfect catch-all system to detect glaucoma suspects. This explains, in part, why an estimated one-third of people in the UK with POAG remain undiagnosed. ${ }^{17}$

Our aim was to offer one glaucoma-related eye health check and one general health check. The health checks offered were limited by the restricted space of the PopUp. Furthermore, people were to be recruited while in shopping centres, so the health checks needed to be quickly administered. For the general health check, a blood pressure (BP) measurement was the obvious choice as it is a quick and non-invasive test. VF tests, optic disc assessment and IOP measurement were all considered for the glaucoma-related measurement. VF tests were discounted due to the size of instruments and test duration plus the challenges of controlling examination conditions (eg, illumination). Optic disc assessment was discounted as two bulky slit-lamp biomicroscopes and/or retinal imaging devices would be required and pupil dilation was not feasible. IOP measurement with hand-held, portable equipment was thought to be feasible. Importantly, it was easy to align the concept of 'pressure' with both IOP and BP measurements in order to encourage public engagement with the Pop-Up.

The primary aim of the study was to investigate the feasibility of performing IOP assessments on large numbers of the public in a shopping centre Pop-Up environment. We tested the specific hypothesis that a Pop-Up combining an IOP check with a general health check such as BP engages the public more than one offering an IOP check only. We also investigated public awareness of IOP compared with $\mathrm{BP}$ and the time participants self-report having last visited an optometrist for an eye examination. We describe the distribution of IOP measurements acquired using a rebound hand-held tonometer and report participants' views on the acceptability of this device.

\section{METHODS}

This was a prospectively planned cross-sectional study designed to capture IOP and BP measurements in people using a Pop-Up in shopping centres throughout England. Our 'Feeling the Pressure' Pop-Up was designed for use in covered areas (). The Pop-Up comprised two private testing areas and an open reception space designed to engage the public. The Pop-Up was assembled for two consecutive working days in eight different shopping centres across England during August 2016. The Pop-Up was open between 09:00 and 17:30 on each testing day and was continuously open for testing between these times. On one day at each centre, the Pop-Up offered both BP and IOP checks, and on the other day it offered an IOP check only. The order of these days was randomised between centres, and all tests were free of charge. Results from the BP measurements are not the subject of this paper and are discussed in another report. ${ }^{18}$

Written, informed consent was obtained from each participant prior to examination.

The 'Feeling the Pressure' Pop-Up was sited in eight different shopping centres: (initials of testing optometrists in parenthesis): Bristol, The Galleries (LAE \& PC); Cambridge, Grafton Centre (LAE, PC \& DJT); Coventry, Lower Precinct (LAE \& PC); Northampton, Weston Favell (LAE \& RS); Nottingham, Intu Broadmarsh (LAE \& RS); 
Preston, St Georges Shopping Centre (LAE \& DJT); Stoke-on-Trent, Intu Potteries Shopping Centre (LAE, DJT \& AEH); Telford Shopping Centre (LAE, PC \& DJT).

Adults were approached by the recruitment assistants who were student volunteers trained to explain glaucoma, IOP and BP in lay terms. Although members of the public 40 years old or older were our target population, everyone over the age of 18 years could be tested. However, IOP measurements of those younger than 40 years of age were not included in our analysis. Participants wearing contact lenses were excluded from the measurement of IOP, as the Pop-Up environment was not suitable for the removal, storage and re-insertion of contact lenses. Participants with insufficient knowledge of the English language to understand the patient information sheet and the consent form were also excluded. The hygiene regime followed by the optometrists was in line with College of Optometrists' guidance. ${ }^{19}$

On approaching a potential participant, the recruitment assistant would specifically ask, 'Do you know anything about your eye pressure?' and record the appropriate response (YES, NO or DON'T KNOW). If a participant answered 'NO' or 'DON'T KNOW', they were asked a second question as a prompt, 'Have you ever had the puff of air test at the opticians?' A positive response to this question would transfer them into the 'YES' category as this indicated that they were familiar with the test. Participants were then asked, 'do you know anything about your blood pressure?' If a participant answered 'NO' or 'DON'T KNOW', they were also asked a second question, 'Have you ever had the arm cuff test?' A positive response to this question would transfer them into the 'YES' category. Each participant was therefore allocated to a 'YES' or 'NO' category for their awareness of eye pressure and blood pressure. A number of participants independently approached the Pop-Up themselves and asked to be examined. They were asked the same questions by an assistant. Participants were then invited into the Pop-Up for the test(s).

After an invitation to be tested was accepted, the participant information sheet was discussed prior to consent being obtained by the optometrist. Then the participant's postcode, age, mobile telephone number and/or email address were recorded. A short case history was taken by the optometrist, including ocular and general health, and family history of glaucoma and systemic hypertension. For participants who were referred because of the results of the test(s), further details were subsequently obtained including full address, general practitioner (GP) details and date of birth. All participants were also asked when they had their most recent eye examination by an optometrist.

An Icare IC-100 tonometer (Icare, Helsinki, Finland) was used to measure participants' IOP in both eyes. The Icare tonometer requires no anaesthetic and has been shown to be well tolerated by patients. ${ }^{20}$ The tonometer uses a disposable probe; therefore, there is no risk of cross infection. Research studies have demonstrated generally good agreement between Icare tonometry and GAT. ${ }^{20-24}$ The Icare tonometer automatically takes six readings per eye in quick succession, with the average reading displayed as the final IOP measurement.

Referrals for elevated IOP were made in line with guidance that applied at the time of the study. ${ }^{78}$ For IOP measurements above $21 \mathrm{~mm} \mathrm{Hg}$, a repeat measurement was taken. If IOP was measured above $21 \mathrm{~mm} \mathrm{Hg}$ on repeat testing in either eye, the participant was referred. This was either a 'routine' referral (via the GP) for IOPs $>21 \mathrm{~mm} \mathrm{Hg}$ and $<35 \mathrm{~mm} \mathrm{Hg}$ or an asymmetry of IOP $>4$ $\mathrm{mm} \mathrm{Hg}$ between eyes, or an 'emergency' (to accident and emergency, within 24 hours) referral for those with IOP $\geq 35 \mathrm{~mm} \mathrm{Hg}$ in either eye. Those with elevated BP were also referred in line with NICE guidelines ${ }^{25}$ and these results are reported elsewhere. ${ }^{18}$

All participants tested were given their IOP and BP results on separate information leaflets specifically designed for this study. Those who declined to take part were also offered a leaflet (Wordbird Healthcare Communications Agency, London, UK; see online supplementary material).

A random sample of participants were asked about the comfort and acceptability of the Icare. The questions asked after the IOP test were: (1) How comfortable did you find the test? and (2) How anxious did the test make you feel? Responses were recorded on a 5-point Likert scale.

All data were inputted using a tablet-based app specifically designed for this study. The tablets and subsequent data storage were password protected and encrypted. Descriptive statistics and data analysis were carried out using SPSS V.25 (SPSS Inc, Chicago).

All testing was performed by two optometrists drawn from a team of five optometrists involved across the 16 days. For each testing day there were also at least two recruitment assistants from a team of six assistants who helped recruit and gather preliminary data from the public.

\section{Patient and public involvement}

An advisory group (AG), comprising glaucoma patients, a consultant ophthalmologist, senior optometrists and members of UK professional bodies for optometrists (The College of Optometrists and the Association of Optometrists) was established. The AG provided advice on all aspects of the Pop-Up study at regular intervals throughout the project.

\section{RESULTS}

During the 16 days of testing, 858 people who approached the Pop-Up, or were invited to participate, gave a response to the questions about awareness of blood pressure or eye pressure. Only 163 (19\%; 95\% CI 17\% to 22\%) reported some awareness of eye pressure in contrast to $609(71 \%$; $95 \%$ CI $68 \%$ to $74 \%$ ) who reported some awareness of BP. 


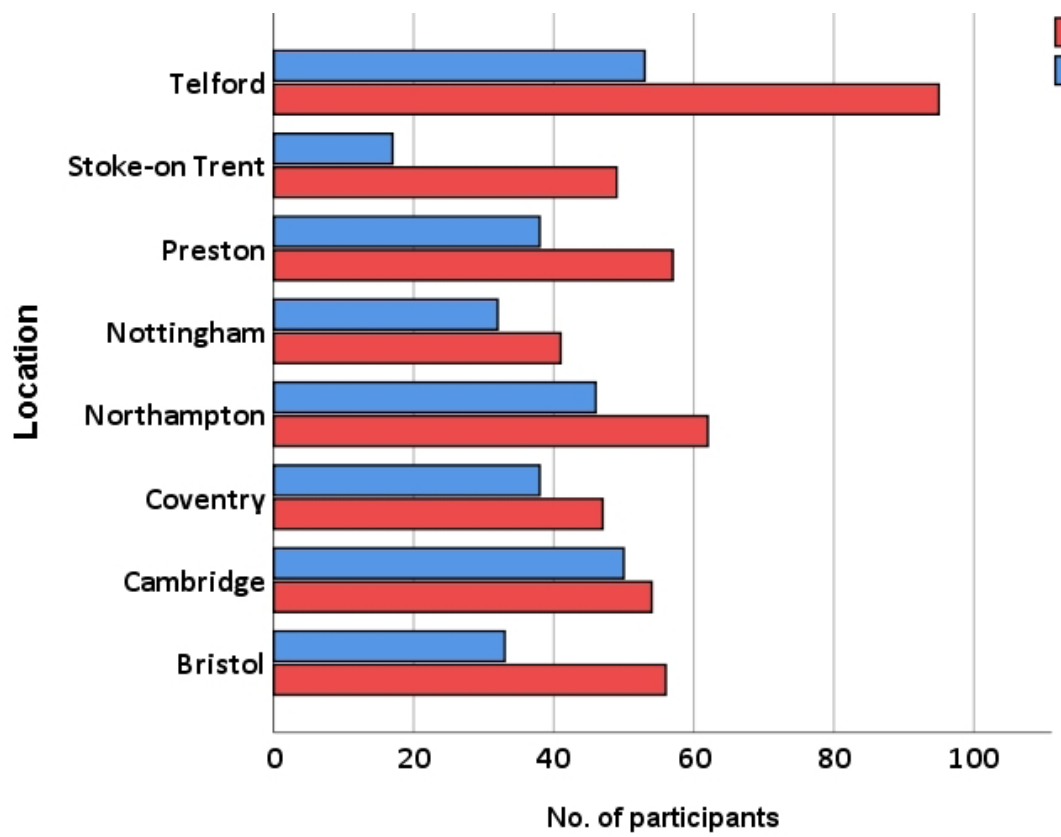

Both tests (BP \& IOP)

IOP only

Figure 2 Number of participants who attended the Pop-Up in each shopping centre stratified by day of testing; IOP test only day or both tests (BP and IOP) day. BP; blood pressure; IOP, intraocular pressure.

From those who responded to these questions, 768 $(90 \%)$ accepted the invitation to be examined in the PopUp. The median (IQR) age of these participants was 54 $(42,68)$ years and $49 \%$ were female. One hundred and fifty-four more participants attended on the combined BP and IOP days $(461 ; 60 \% ; 95 \%$ CI $56 \%$ to $64 \%)$ than on the IOP-only days (307; $40 \%, 95 \%$ CI $37 \%$ to $43 \%)$. The number of participants per shopping centre is illustrated in figure 2. On average, across all sites and all 16 days, one person was examined in the Pop-Up every 10 min.

One hundred and sixteen (15\%) participants were not included in the analysis of IOP data, comprising those who declined to have their IOP measured (38 participants; $5 \%$ ) or were excluded, for example if they were wearing contact lenses (eight participants; 1\%) or were aged 40 years or younger (70 participants; $9 \%$ ).

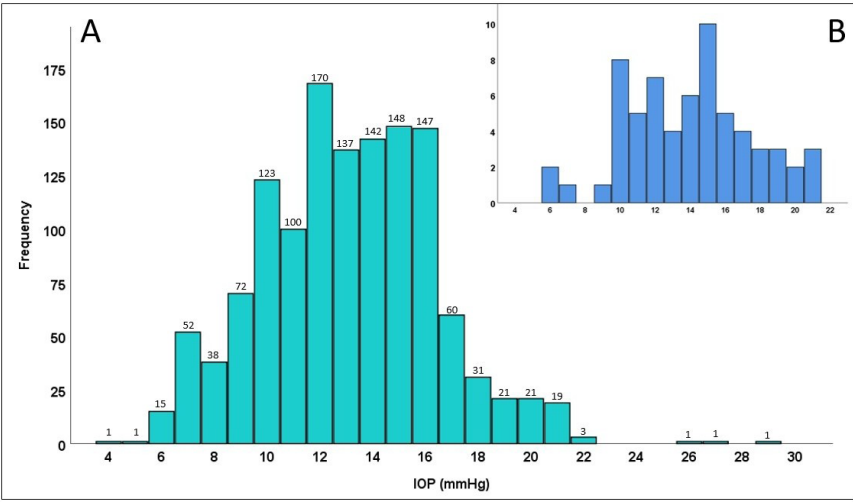

Figure 3 IOP distributions for all 1304 eyes of 652 participants $(A)$ and for 64 eyes of the 32 participants self-reporting ocular hypertension or glaucoma (B). IOP, intraocular pressure.
Median $\left(5^{\text {th }}, 25^{\text {th }}, 75^{\text {th }}\right.$ and $95^{\text {th }}$ percentile) right-eye (RE) IOP and left-eye (LE) IOP were $13(7,11,15,19)$ and $13(8,11,15,19) \mathrm{mm} \mathrm{Hg}$, respectively. Mean IOP for RE and LE were 13.0 (SD of 3.3) and 13.0 (SD 3.2) $\mathrm{mm} \mathrm{Hg}$ respectively. The distribution of all IOP measurements is shown in figure $3 \mathrm{~A}$.

Only four $(0.6 \%)$ participants were referred for elevated IOP, with two having elevated IOP in both eyes, and all were routine referrals rather than emergency with measurements of 22, 22, 27 and $29 \mathrm{~mm} \mathrm{Hg}$ (the eye with the higher IOP reported here for each of these four participants) (figure 3B). Three of these referrals were tested on the joint BP and IOP days. All referrals were 'new' referrals and not participants who were already attending the hospital eye service (HES) for glaucoma or ocular hypertension (OHT). Out of all participants tested, $12(1.8 \%)$ self-reported that they had OHT and 20 (3\%) self-reported that they had glaucoma. For these 32 participants, median $\left(5^{\text {th }}, 25^{\text {th }}, 75^{\text {th }}\right.$ and $95^{\text {th }}$ percentile $)$ RE and LE IOP was $15(7,11,17,21)$ and $14(9,11,16$, 20) $\mathrm{mm} \mathrm{Hg}$, respectively. The IOP distribution for these 32 individuals is shown in figure 3B.

Responses to the question about the last visit to an optometrist were recorded for all 768 participants. In total 523 (68\%; 95\% CI $65 \%$ to $71 \%$ ) participants reported having visited an optometrist within the previous 2 years and 185 (24\%; $95 \%$ CI $21 \%$ to $27 \%$ ) reported that their last visit was more than 2 years ago. Sixty participants (8\%; $95 \%$ CI $6 \%$ to $10 \%)$ reported that they had never had an eye examination from an optometrist and 44 of these (73\%; 95\% CI 60\% to 84\%) attended our Pop-Up on the days during which we offered both BP and IOP testing. Although more participants $(60 \%)$ attended on 
the BP and IOP testing days, this $73 \%$ figure was greater than would be expected by chance $(\mathrm{p}=0.03$; comparison of two binomial proportions).

A sample of 350 participants completed the questionnaire regarding the Icare. Overall, 305 (87\%; 95\% CI 83\% to $90 \%$ ) participants rated the tonometer 'very comfortable' or 'comfortable'. In addition, 298 (85\%; 95\% CI $81 \%$ to $88 \%$ ) reported that the Icare caused 'no anxiety' or 'little anxiety'.

\section{DISCUSSION}

Our study has established that measuring IOP in large numbers of the public via a Pop-Up in a shopping centre is feasible. Participant throughput was high, with someone being examined every 10 minutes on average. Measuring IOP with an Icare tonometer in a shopping centre Pop-Up environment was acceptable and rated as comfortable by a large majority of participants. To our knowledge there has been no other study utilising a Pop-Up for the purpose of BP and IOP measurements. Specifically, this study has shown that more people had their IOP measured when this test was offered in conjunction with a BP test. It is assumed that our attempts to encourage people to take part were the same across each of the 2 days when the different conditions were tested. In fact, there was no active recruitment as such and the attraction to the Pop-Up at all sites, and on all days was noteworthy. Hence, our 'Feeling the Pressure' approach suggests an unfamiliar health message can be promoted by aligning it with one that the public is more conversant with, such as BP measurement. This is relevant in the context of ocular health; previous research in the UK has concluded that raising understanding about the purpose of eye examinations in terms of preventable sight loss, not just the need for spectacles, should be an important health message. ${ }^{1526}$

Our simple questions posed to potential participants revealed that only one in five people reported having any awareness of IOP. Notably, these potential participants included at least 32 people already under the care of the HES for either OHT or glaucoma, who are very likely to be aware of IOP. Conversely, the majority of those questioned $(71 \%)$ reported that they were aware of BP. This is the only study of which we are aware that estimates public awareness of IOP. Previous research established that good knowledge of BP influences BP control in a hypertensive population and has important public health implications. ${ }^{27}$ Some interventions have been put in place in order to increase public awareness of their BP; for example, the "Know Your Numbers" campaign encourages adults to learn about their BP 'numbers' and to educate them on the actions that could be taken to maintain a healthy $\mathrm{BP}^{28}{ }^{2}$ In addition, the National Health Service health check, ${ }^{29}$ a targeted initiative for examining general health in older adults, includes an assessment of BP with personalised advice on how to lower BP. Educating the public regarding the importance of regular eye examinations and risk factors for glaucoma would seem a sensible public health strategy, as advocated more than 20 years ago. ${ }^{30}$ Moreover, lack of awareness of glaucoma and other eye conditions has negative implications for the uptake of optometric care. ${ }^{31-33}$ Easily accessible testing opportunities such as those in community settings or the workplace have been shown to be a strategy for identifying elevated BP in the public. ${ }^{14} 34$ Similar strategies could be useful for assessing IOP, with the added advantage of reducing the anxiety of examination in a 'white coat' medical environment. ${ }^{35} 36$

It is important to note that the purpose of our study was not to diagnose glaucoma; we measured IOP only and there was no attempt to use other tests or combinations of tests with the potential to detect glaucoma. The diagnostic capability of an IOP measurement alone is poor and hence formal diagnosis of glaucoma is based on the results from an array of tests, including tonometry, assessment of the optic nerve head, VF assessment, pachymetry and assessment of the anterior chamber angle, most commonly determined by gonioscopy. ${ }^{5173738}$ Although the diagnosis of glaucoma was not the purpose of the Pop-Up, we aimed to inform people in the shopping centres of the importance of measuring IOP and having regular eye examinations; we speculate this information could lead to possible long-term benefits in terms of their ocular health. Only four $(0.6 \%)$ participants were referred routinely for elevated IOP; these were 'new' referrals and not participants who self-reported that they were already attending the HES for glaucoma or OHT. A meta-analysis found the prevalence of POAG for Europeans between 40 and 80 years old was $2.51 \%$ (1.54\% to $3.89 \%)^{39}$ and the prevalence of OHT has been estimated to be between $3 \%$ and $5 \%$ for those over the age of 40 years. ${ }^{40}$ In our participants, 32 people $(4.9 \%)$ who had their IOP measured self-reported that they were already under the care of the HES for glaucoma or OHT. So, our estimate of people with elevated IOP is still slightly lower than the expected percentage in a population-based study. There are at least two possible explanations for this. First, people with a diagnosis of glaucoma or OHT may be less likely to engage with a Pop-Up offering an eye pressure check and this might have influenced our estimates. Second, it is possible that the Icare IC-100 model gives systematically lower IOP measurements than GAT which is the reference standard for measurement of IOP. This bias towards lower IOP readings with this Icare model has also been observed in two other recent studies. ${ }^{41} 42$ It was emphasised to all participants that an IOP below our referral threshold did not necessarily mean that they did not have glaucoma. Furthermore, it was stressed to all participants that the Pop-Up check was no substitute for a full eye examination by an optometrist; this message was reinforced with an information leaflet about IOP given to all participants (see online supplementary material). This advice was based on evidence that OHT cannot be diagnosed from a single IOP measurement and that diurnal variation in IOP plays an important role in its 
measurement. ${ }^{43}$ Furthermore, it is estimated that half of those people with a diagnosis of POAG present with IOP less than or equal to $21 \mathrm{~mm} \mathrm{Hg} .{ }^{17}$ The measurement of IOP was well accepted and tolerated by our participants. Although there are several research papers exploring older Icare models and their comparability to GAT, there is limited literature on the IC-100 model. In a systematic review evaluating different tonometers, older models of the Icare generally had good agreement with GAT, the current reference standard for IOP measurement. ${ }^{4244}$ Icare tonometry is widely used in community optometric practices and in some secondary care services, in particular in paediatric ophthalmology clinics. ${ }^{45-47}$ The advantages of Icare tonometry include the portability of the device, rapid speed of measurement and the fact that there is no need to instil topical anaesthetic or fluorescein.

The Pop-Up engaged members of the public who were not routinely engaged with primary optometric care. In particular, $8 \%$ of participants self-reported that they had never previously had an eye examination from an optometrist. Our findings are not dissimilar to a survey conducted by the College of Optometrists, in which $5 \%$ of people aged over 40 years reported that they had not been for an eye examination for at least 10 years or could not recall when they had last visited an optometrist. ${ }^{48}$ Interestingly, $73 \%$ of those who self-reported never visiting an optometrist attended our Pop-Up on the days on which we offered both BP and IOP testing, a significantly greater proportion than might be expected by chance even though a greater percentage of participants attended on the BP plus IOP testing days. Furthermore, out of the 38 participants who declined an IOP measurement, a large proportion (31 participants; 82\%) had undergone an eye examination within 4 months of their visit to the Pop-Up. It could be speculated that these individuals did not want their IOP to be checked again as they were aware it had been measured recently by their optometrist. Both of these points further support the idea of combining an eye examination with other health checks in order to reach members of the public who may not otherwise visit their optometrist.

Although not the main subject of this report, a brief consideration of the cost-effectiveness of the Pop-Up is pertinent. Operational costs, including installation, crew, transport, site related costs and project management were 26700 GBP for the 16 days. There were no costs for the research team who staffed the Pop-Up itself, but we assume these to be 500 GBP per day (two qualified optometrists and assistants). Therefore, each Pop-Up examination cost approximately 45 GBP per person ( $(26$ $700+8000) / 768)$; this seems high given an appointment with a GP was recently estimated to cost approximately 30 GBP. $^{49}{ }^{50}$ Moreover, we referred only four people for suspect ocular hypertension; even if they were all diagnosed as cases, which is unlikely, then the cost per detected case would be 8675 GBP. For context, a recent study assessing a GP based detection scheme in London, targeting people at high risk of glaucoma, yielded a cost per case identified with suspected or confirmed glaucoma of 9013 GBP. ${ }^{51}$ Our simple calculations exclude the outlay of the designing/fabricating of the 'Feeling the Pressure' Pop-Up which was approximately 33000 GBP. Taken together the costs per case identified in our study are high especially in relation to figures from systematic reviews of other screening and case-detection schemes. ${ }^{52-55}$ Still, a fairer assessment of the overall cost effectiveness of the 'Feeling the Pressure' Pop-Up ought to consider our case finding of elevated BP as reported elsewhere.$^{18}$ In addition, willingness to pay could be considered; we collected data on this with a post-study questionnaire and this will be the subject of a further report.

There are some limitations to our study. Questioning the public on their awareness of BP or IOP may have resulted in some people answering 'NO' to this question when they did have some awareness of IOP or BP, either because they did not wish to participate in the study or did not want to be questioned further. Similarly, some members of the public may have said 'YES' to these questions when they had no awareness but did not want to appear unaware. Furthermore, when data was collected, refusal rates for each site were pooled together, so we are unable to distinguish between those who refused on IOP only testing days or those who refused on IOP plus BP testing days. Finally, some members of the public did not answer the questions regarding awareness of blood pressure or eye pressure when they were approached. It is impossible to quantify how many people avoided the Pop-Up and we have not quantified those who declined to answer the questions. Therefore, the overall response rate will be lower than the $90 \%$ documented in our results.

Furthermore, the questions asked regarding awareness of IOP and BP were very basic and superficial. Despite this, there was a clear difference between the proportions of people who reported knowing something about BP compared with knowing something about IOP. Limitations of response bias and recall bias apply to our estimates of participants self-reporting the time since their last eye examination with an optometrist. Moreover, the data obtained from the Icare questionnaire are limited to being descriptive only and we do not compare the data with other testing modalities. A further critical limitation of our study is that we do not report participant ethnicity; this could be an important drawback because glaucoma is more prevalent in certain racial groups. ${ }^{56-59}$

In closing, there is a public health need to increase the detection rate of glaucoma suspects; testing in targeted community settings has been suggested as a solution ${ }^{60}$ and this might be facilitated by a Pop-Up approach as described in our work. This could be especially true if it could be combined with other eye health checks. We show in this novel study that it is possible to offer IOP measurements in a healthcare Pop-Up and this approach is well accepted by large numbers of the public in shopping centres, even though awareness of IOP is generally lacking. More people engaged with the Pop-Up on days when two health checks were offered, suggesting that an 
unfamiliar health message can be promoted by aligning it with one that the public is more familiar with. Our findings hint at strategies for public health schemes that engage the public with their eye health and promote education about the importance of regular eye examinations.

\section{Twitter Deanna J Taylor @crabblab}

Acknowledgements The authors thank Sarah Sowerby, Andrew Nicholson and Colm 0'Connor, of Wordbird Healthcare Communications Agency (http:// www.wordybirdy.co.uk/) for designing and creating the 'Feeling the Pressure' theme and information leaflets. We also thank Bluedog Productions (http://www. bluedogproductions.co.uk/) for building the Pop-Up and logistics. We also thank the volunteer recruitment assistants: Amy-Lee Bassage, Susan Bryan, Lucy Edwards, Lee Jones, Mandeep Kaur-Bains, Leanne McDonald and study optometrist Angharad Hobby. We also thank the advisory group members for their input in the design and development of this study. Two Icare IC-100 tonometers were donated by Mainline Instruments Ltd, UK and Icare, Finland.

Contributors LAE performed study design, data collection, data analysis and manuscript preparation. DJT performed data collection and manuscript critique. PC performed data collection and manuscript critique. RS performed data collection and manuscript critique. DFE performed study design and manuscript critique. DPC performed study design, data analysis and manuscript critique.

Funding This project was supported in part by an unrestricted regional funding grant from Allergan Inc. and a grant from the International Glaucoma Association (IGA)/College of Optometrists research award (which is funded by the IGA and administered by the IGA in conjunction with the College of Optometrists).

Competing interests None declared.

Patient consent for publication Not required.

Ethics approval The study was approved by City, University of London Senate Research Ethics Committee and was conducted according to the tenets of the Declaration of Helsinki.

Provenance and peer review Not commissioned; externally peer reviewed.

Data availability statement All data relevant to the study are included in the article or uploaded as supplementary information.

Open access This is an open access article distributed in accordance with the Creative Commons Attribution Non Commercial (CC BY-NC 4.0) license, which permits others to distribute, remix, adapt, build upon this work non-commercially, and license their derivative works on different terms, provided the original work is properly cited, appropriate credit is given, any changes made indicated, and the use is non-commercial. See: http://creativecommons.org/licenses/by-nc/4.0/.

ORCID iD

Laura A Edwards http://orcid.org/0000-0002-0886-8520

\section{REFERENCES}

1 Centre for Economics and Business Research Ltd. Pop-up retailing produced £2.1 billion in retail turnover in the past year. Available: https://wwwcebrcom/reports/pop-up-retailing-produced-2-1-billionin-retail-turnover-in-the-past-year/ 2014; Centre for Economics and Business Research

2 Surchi M. The temporary store: a new marketing tool for fashion brands. Journal of Fashion Marketing and Management: An International Journal 2011;15:257-70.

$3 \mathrm{Kim} \mathrm{H}$, Fiore AM, Niehm LS, et al. Psychographic characteristics affecting behavioral intentions towards pop-up retail. Int/ J of Retail \& Distrib Mgt 2010;38:133-54.

4 Hellman B, Ghosh T, Narayana R. Popup clinic: your health in your hands. Int J Integr Care 2014;14.

5 King A, Azuara-Blanco A, Tuulonen A. Glaucoma. BMJ 2013;346.

6 Quartilho A, Simkiss P, Zekite A, et al. Leading causes of certifiable visual loss in England and Wales during the year ending 31 March 2013. Eye 2016;30:602-7.

7 Guidance on the referral of glaucoma suspects by community optometrists: issued by the College of Optometrists and the Royal College of Ophthalmologists. Available: http://www.collegeoptometrists.org/en/utilities/document-summary.cfm/docid/ B7251E0C-2436-455A-B15F1E43B6594206
8 NICE. Glaucoma: diagnosis and management, Clinical guideline [CG85], 2009. Available: https://www.nice.org.uk/guidance/CG85

9 Bowling B, Chen SDM, Salmon JF. Outcomes of referrals by community optometrists to a hospital glaucoma service. $\mathrm{Br} J$ Ophthalmol 2005;89:1102-4.

10 Gunn PJG, Marks JR, Konstantakopoulou E, et al. Clinical effectiveness of the Manchester glaucoma enhanced referral scheme. Br J Ophthalmol 2019;103:1066-71.

11 Theodossiades J, Murdoch I. Positive predictive value of optometrist-initiated referrals for glaucoma. Ophthalmic Physiol Opt 1999;19:62-7.

12 Lau JTFet al. Knowledge about cataract, glaucoma, and age related macular degeneration in the Hong Kong Chinese population. $\mathrm{Br} \mathrm{J}$ Ophthalmol 2002;86:1080-4.

13 Livingston PM, McCarty CA, Taylor HR. Knowledge, attitudes, and self care practices associated with age related eye disease in Australia. Br J Ophthalmol 1998;82:780-5.

14 Caligiuri SPB, Austria JA, Pierce GN. Alarming prevalence of emergency hypertension levels in the general public identified by a hypertension awareness campaign. Am J Hypertens 2017;74:hpw136-9.

15 Shickle D, Griffin M. Why don't older adults in England go to have their eyes examined? Ophthalmic Physiol Opt 2014;34:38-45.

16 Green J, Siddall H, Murdoch I. Learning to live with glaucoma: a qualitative study of diagnosis and the impact of sight loss. Soc Sci Med 2002;55:257-67.

17 Chan MPY, Broadway DC, Khawaja AP, et al. Glaucoma and intraocular pressure in EPIC-Norfolk eye study: cross sectional study. BMJ 2017;358.

18 Edwards LA, Campbell P, Taylor DJ, et al. Healthy shopper? blood pressure testing in a Shopping centre Pop-Up in England. BMC Public Health 2019;19:42.

19 The College of Optometrists. Methods of preventing infection transmission from person to person. Available: https://guidance. college-optometrists.org/guidance-contents/safety-and-qualitydomain/infection-control/methods-of-prevention-hand-hygiene/2016

20 Brusini P, Salvetat ML, Zeppieri M, et al. Comparison of ICARE tonometer with Goldmann applanation tonometer in glaucoma patients. J Glaucoma 2006;15:213-7.

21 Pakrou N, Gray T, Mills R, et al. Clinical comparison of the Icare tonometer and Goldmann applanation tonometry. J Glaucoma 2008;17:43-7.

22 Fernandes P, Díaz-Rey JA, Queirós A, et al. Comparison of the Icare rebound tonometer with the Goldmann tonometer in a normal population. Ophthalmic Physiol Opt 2005;25:436-40.

23 Wong B, Parikh D, Rosen L, et al. Comparison of disposable Goldmann applanation tonometer, Icare IC-100, and Tonopen XL to standards of care Goldmann nondisposable applanation tonometer for measuring intraocular pressure. J Glaucoma 2018;27:1119-24.

24 Davies LN, Bartlett H, Mallen EAH, et al. Clinical evaluation of rebound tonometer. Acta Ophthalmol Scand 2006;84:206-9.

25 National Institute for Health and Care Excellence. Hypertension in adults: diagnosis and management. Available: https://www.nice. org.uk/guidance/cg127/chapter/1-Guidance\#measuring-bloodpressure2016

26 Shickle D, Griffin M, Evans R, et al. Why don't younger adults in England go to have their eyes examined? Ophthalmic Physiol Opt 2014;34:30-7.

27 Slark J, Khan MS, Bentley P, et al. Knowledge of blood pressure in a U.K. General public population. J Hum Hypertens 2014;28:500-3.

28 Cadilhac DA, Kilkenny MF, Johnson R, et al. The know your numbers (KYN) program 2008 to 2010: impact on knowledge and health promotion behavior among participants. Int J Stroke 2015;10:110-6.

29 Martin A, Saunders CL, Harte E, et al. Delivery and impact of the NHS health check in the first 8 years: a systematic review. $\mathrm{Br} J$ Gen Pract 2018;68:e449-59.

30 Livingston PM, Lee SE, De Paola C, et al. Knowledge of glaucoma, and its relationship to self-care practices, in a population sample. Aust N Z J Ophthalmol 1995;23:37-41.

31 Katibeh M, Ziaei H, Panah E, et al. Knowledge and awareness of age related eye diseases: a population-based survey. J Ophthalmic Vis Res 2014;9:223-31.

32 Baker H, Murdoch IE. Can a public health intervention improve awareness and health-seeking behaviour for glaucoma? $\mathrm{Br} J$ Ophthalmol 2008;92:1671-5.

33 Mansouri K, Orgül S, Meier-Gibbons F, et al. Awareness about glaucoma and related eye health attitudes in Switzerland: a survey of the general public. Ophthalmologica 2006;220:101-8.

34 O'Brien E, Beevers G, Lip GY. Abc of hypertension: blood pressure measurement. Part IV-automated sphygmomanometry: self blood pressure measurement. BMJ 2001;322:1167-70. 
35 Dryden R, Williams B, McCowan C, et al. What do we know about who does and does not attend general health checks? findings from a narrative scoping review. BMC Public Health 2012;12:723.

36 Brody S, Erb C, Veit R, et al. Intraocular pressure changes: the influence of psychological stress and the Valsalva maneuver. Biol Psychol 1999;51:43-57.

37 King A, Migdal C. Clinical management of glaucoma. J R Soc Med 2000;93:175-7.

38 Jampel HD. Screening for glaucoma using intraocular pressure alone. BMJ 2017.

39 Tham Y-C, Li X, Wong TY, et al. Global prevalence of glaucoma and projections of glaucoma burden through 2040. Ophthalmology 2014;121:2081-90.

40 Royal College of Ophthalmologists. Commissioning guide: glaucoma. Available: https://www.rcophth.ac.uk/wp-content/uploads/2016/06/ Glaucoma-Commissioning-Guide-Long-June-2016-Final.pdf;

41 Susanna BN, Ogata NG, Daga FB, et al. Association between rates of visual field progression and intraocular pressure measurements obtained by different tonometers. Ophthalmology 2019;126:49-54.

42 Aurora GYOS, Paczka JA, Romo Sainz M, et al. Comparison of three methods to measure intraocular pressure IC-100 Icare, TAO1i ICARE and Goldmann applanation tonometry. Investigative Ophthalmology \& Visual Science 2017;58.

43 Shah S, Spedding C, Bhojwani R, et al. Assessment of the diurnal variation in central corneal thickness and intraocular pressure for patients with suspected glaucoma. Ophthalmology 2000;107:1191-3.

44 Cook JA, Botello AP, Elders A, et al. Systematic review of the agreement of tonometers with Goldmann applanation tonometry. Ophthalmology 2012;119:1552-7.

45 Grigorian F, Grigorian AP, Olitsky SE. The use of the Icare tonometer reduced the need for anesthesia to measure intraocular pressure in children. J Aapos 2012;16:508-10.

46 Kageyama M, Hirooka K, Baba T, et al. Comparison of ICARE rebound tonometer with noncontact tonometer in healthy children. $J$ Glaucoma 2011;20:63-6.

47 Sahin A, Basmak H, Niyaz L, et al. Reproducibility and tolerability of the ICARE rebound tonometer in school children. $J$ Glaucoma 2007;16:185-8.
48 The College of Optometrists. Britain's eye health in focus: a study of consumer attitudes and behaviour towards eye health London, 2011.

49 lacobucci G. Sixty seconds on ... missed GP appointments. BMJ 2019;364.

50 Oliver D. David Oliver: missed GP appointments are no scandal. BMJ 2019;364.

51 Holdsworth E, Datta J, Marks D, et al. A mixed-methods evaluation of a community-based glaucoma check service in Hackney, London, UK. Ophthalmic Epidemiol 2017;24:248-56.

52 Pizzi LT, Waisbourd M, Hark L, et al. Costs of a community-based glaucoma detection programme: analysis of the Philadelphia glaucoma detection and treatment project. $\mathrm{Br} \mathrm{J}$ Ophthalmol 2018;102:225-32.

53 Blumberg DM, Vaswani R, Nong E, et al. A comparative effectiveness analysis of visual field outcomes after projected glaucoma screening using SD-OCT in African American communities. Invest. Ophthalmol. Vis. Sci. 2014;55:3491-500.

54 Anton A, Fallon M, Cots F, et al. Cost and detection rate of glaucoma screening with imaging devices in a primary care center. Clin Ophthalmol 2017;11:337-46.

55 Thomas S-M, Jeyaraman M, Hodge WG, et al. The effectiveness of Teleglaucoma versus in-patient examination for glaucoma screening: a systematic review and meta-analysis. PLoS One 2014;9:e113779.

56 Chen PP. Blindness in patients with treated open-angle glaucoma. Ophthalmology 2003;110:726-33.

57 Racette L, Wilson MR, Zangwill LM, et al. Primary open-angle glaucoma in blacks: a review. Surv Ophthalmol 2003;48:295-313.

58 Hattenhauer MG, Johnson DH, Ing HH, et al. The probability of blindness from open-angle glaucoma. Ophthalmology 1998;105:2099-104.

59 Cheng J-W, Zong Y, Zeng Y-Y, et al. The prevalence of primary angle closure glaucoma in adult Asians: a systematic review and metaanalysis. PLoS One 2014;9:e103222.

60 Burr J, Mowatt G, Hernández R, et al. The clinical effectiveness and cost-effectiveness of screening for open angle glaucoma: a systematic review and economic evaluation. Health Technol Assess 2007;11:1-190. 